OPEN ACCESS

Edited by:

Carolina Escobar,

University of Castilla La Mancha,

Spain

Reviewed by:

Cheng-Guo Duan,

Shanghai Institutes for Biological

Sciences (CAS), China

Mathew G. Lewsey,

La Trobe University, Australia

*Correspondence:

Laurent Zimmerl

lozim4@gmail.com

Specialty section:

This article was submitted to

Plant Microbe Interactions,

a section of the journal

Frontiers in Plant Science

Received: 16 August 2019 Accepted: 12 November 2019 Published: 18 December 2019

Citation:

Chan C and Zimmerli L (2019) The Histone Demethylase IBM1 Positively

Regulates Arabidopsis Immunity by Control of Defense Gene Expression.

Front. Plant Sci. 10:1587. doi: 10.3389/fp/s.2019.01587

\section{The Histone Demethylase IBM1 Positively Regulates Arabidopsis Immunity by Control of Defense Gene Expression}

\author{
Ching Chan and Laurent Zimmerli* \\ Department of Life Science and Institute of Plant Biology, National Taiwan University, Taipei, Taiwan
}

Epigenetic modifications involve complex and sophisticated control over chromatin states and DNA methylation patterns, which are important for stress tolerance in plants. While the identification of epigenetic modulating enzymes keeps growing, such as MET1, for CG methylation; CMT3, DRM2, DRM3 for CHH methylation; and IBM1, SUVH4 for CHG methylation; the molecular roles of these regulators in specific physiological functions remain obscure. In a mutant screen, we identified IBM1 as a new player in plant immunity. The ibm1 mutants were hyper-susceptible to hemi-biotrophic bacteria Pseudomonas syringae. Accordingly, bacteria-induced up-regulation of PR1, PR2, and FRK1 defense markers was abolished in ibm1 mutants. Consistently, at the chromatin level, these defense marker genes showed enrichment of the inactivation mark, H3K9me2; while the activation mark $\mathrm{H} 3 \mathrm{~K} 4 \mathrm{me} 3$ was reduced in ibm 1 mutants. Immunoprecipitation of associated chromatin further demonstrated that IBM1 binds directly to the gene body of $P R 1, P R 2$, and $F R K 1$. Taken together, these data suggest that IBM1 plays a critical role in modulating Arabidopsis immunity through direct regulation of defense gene expression. Notably, IBM1 maintains a permissive chromatin environment to ensure proper induction of defense genes under some biotic stress.

Keywords: Arabidopsis, innate immunity, epigenetic regulator, IBM1, bacteria, defense, chromatin

\section{INTRODUCTION}

Epigenetic control of the plant immunity response provides plasticity for the dynamic regulation of emerging pathogens, and at the same time maintains genome stability to avoid the generation of genomic lesion (Fu and Dong, 2013; Espinas et al., 2016). Response to pathogen-associated molecular pattern (PAMP)- or pattern-triggered immunity (PTI) and effector-triggered immunity (ETI) involves extensive transcriptional reprogramming (Tsuda and Katagiri, 2010; Huang and Zimmerli, 2014). In general, the plant defense response against biotrophic pathogens is mediated by salicylic acid (SA)-dependent signaling, while signals for resistance to necrotrophs occur through the jasmonic acid/ethylene (JA/ET) pathway (Katagiri et al., 2002; Alvarez et al., 2010). Crosstalk between the two pathways are well balanced to ensure priority of defense against either biotrophic or necrotrophic attack. Depending on the concentration of SA and JA, the two pathways can work synergistically or antagonize each other (Koornneef and Pieterse, 2008; Bari and Jones, 2009; Vlot et al., 2009). Eventually, both signaling cascades converge at the expression of antimicrobial pathogenesisrelated (PR) genes in local environment as well as in distal tissue for long-term protection. 
Moreover, local defense responses can trigger a second layer of protection at distal tissue to protect the rest of the plant from subsequent infection, this phenomenon is known as systemic acquired resistance (SAR) (Fu and Dong, 2013).

Recent studies on epigenetic modifications and chromosome architecture brought novel insights beyond the concept of latentstate immune signaling component. "Immune memory" can last for weeks, months, the whole season, or even be passed on to progenies (Luna et al., 2012; Fu and Dong, 2013; Singh et al., 2014). In general, loss of DNA methylation makes plants more resistant to bacterial infection. For example, mutants defective in maintenance of CG methylation, met1-3, and non-CG methylation, $d d c$, are highly resistant to Pseudomonas syringae pv. tomato (Pst) infection (Dowen et al., 2012). INCREASE IN BONSAI METHYLATION 1 (IBM1) negatively regulates $\mathrm{CHG}$ methylation in genic regions and mediates multiple developmental phenotypes, including flower and seed development (Saze et al., 2008). Mutants of IBM1 demonstrate ectopic accumulation of $\mathrm{H} 3 \mathrm{~K} 9 \mathrm{me}$ and $\mathrm{CHG}$ methylation, which are suppressed by mutation of KYP/SUVH4 or CMT3 (Saze et al., 2008). Genome-wide analysis of DNA methylation revealed that thousands of genes were hyper-methylated at CHG sites in ibm 1 mutants (Miura et al., 2009). Unlike DDM1, which controls CHG methylation at transposable element, pseudogenes, and repeat elements, $i b m 1$ mutation mainly affects long transcribed genes (Miura et al., 2009). IBM1 encodes a jumonji C (jmjC) domain, conserved for histone demethylase activity. JmjC demethylases preferentially remove monomethylated and dimethylated histone lysines (Inagaki et al., 2010), through an oxidative reaction that requires ferrous ion $[\mathrm{Fe}(\mathrm{II})]$ and $\boldsymbol{\alpha}$-ketoglutate as cofactors (Tsukada et al., 2006). Altogether, there are 21 annotated jmjC domain-containing protein in Arabidopsis thaliana and their roles in plant immunity is largely untouched. For instance, a few orphan studies recently demonstrated that JMJ704 and JMJ705 regulate defense in rice (Li et al., 2013; Hou et al., 2015).

Here, we report that IBM1 positively regulates Arabidopsis defenses against the hemi-biotrophic pathogen Pst DC3000. Loss of IBM1 repressed defense genes induction upon bacteria infection and PAMP perception. At the chromatic level, the reduced gene expression was associated with repressive $\mathrm{H} 3$ modifications. In addition, IBM1 directly associated with the gene body of $P R 1, P R 2$, and FRK1 defense genes. We also explored the role of IBM1 in other defense pathways, including systemic acquired resistance, PTI, and defense against the necrotrophic pathogen, Botrytis cinerea. Overall, we revealed a novel role for IBM1 to maintain a permissive chromatin environment to ensure proper induction of defense genes under biotic stress.

\section{MATERIALS AND METHODS}

\section{Plant and Pathogen Materials}

Arabidopsis thaliana ecotype Col-0 and the mutants, ibm1-3 (SALK_023533) and ibm1-4 (SALK_035608), were obtained from the Arabidopsis Biological Resource Center (http://abrc.osu. $\mathrm{edu} /$ ). Seeds were surface sterilized in $10 \%$ bleach, washed with sterilized water, and kept for 3 days at $4^{\circ} \mathrm{C}$. The sterilized seeds were then dispersed on 1/2 Murashige and Skoog (MS) medium containing $1 \%$ agar and grown for 14 days, under photosynthetic illumination $\left(100 \mu \mathrm{E} \mathrm{m}^{-2} \mathrm{~s}^{-1}\right)$ and short day condition (9-h-light, $22^{\circ} \mathrm{C} / 15$-h-dark, $18^{\circ} \mathrm{C}$ ). Alternatively, seeds were stratified for 3 days, sown on commercial potting soil/perlite (3:2), and grown for 5 weeks, under the same growth conditions.

P. syringae pv. tomato (Pst) DC3000 and avirulent Pst DC3000 (avrRpt2) bacteria were obtained from B.N. Kunkel (Washington University, St. Louis, Missouri, USA). Pst DC3000 bacteria were grown at $28^{\circ} \mathrm{C}$ in King's B medium supplemented with 50 $\mathrm{mg} / \mathrm{L}$ rifampicin (Yekondi et al., 2017), and supplemented with $50 \mathrm{mg} / \mathrm{L}$ rifampicin and $50 \mathrm{mg} / \mathrm{L}$ kanamycin for Pst DC3000 (avrRpt2) bacteria.

The fungus $B$. cinerea (B071) was kindly provided by C.Y. Chen (National Taiwan University, Taipei, Taiwan). B. cinerea was grown at room temperature on potato dextrose agar (PDB)agar plates as previously described (Zimmerli et al., 2001; Yekondi et al., 2017).

\section{Pathogen Infection Assays}

For surface inoculation, 5-week-old plants were dip-inoculated with $10^{6} \mathrm{cfu} / \mathrm{ml}$ Pst DC3000 bacteria for $15 \mathrm{~min}$ and kept at $100 \%$ relative humidity for one night. Bacterial titers were quantified 3 days later on Kirby-Bauer (KB) agar plates as described previously (Huang et al., 2013). For infiltration inoculation, three fully expanded leaves of 5-week-old plants were infiltrated on the abaxial surface with $10^{5} \mathrm{cfu} / \mathrm{ml}$ Pst DC3000 bacteria using a needleless syringe. Bacterial titers were quantified on KB agar plates as described (Huang et al., 2013), after 3 days. For the systemic acquired resistance assay, three fully expanded leaves of 5-week-old plants were first infiltrated with $10^{7} \mathrm{cfu} /$ $\mathrm{ml}$ Pst DC3000 (avrRpt2). Three other leaves were infiltrated 3 days later with $10^{5} \mathrm{cfu} / \mathrm{ml}$ Pst DC3000. Bacterial titers were quantified on KB agar plates as described (Huang et al., 2013), after 3 days. B. cinerea spores were diluted to $10^{5}$ spores $/ \mathrm{ml}$ in $1 / 2$ PDB medium and $10 \mu \mathrm{l}$ droplets were deposited on leaf surface of 5-week-old plants (three leaves per plant). Leaves of the same age were chosen for droplet-inoculation. Plants were then kept at $100 \%$ relative humidity and lesion perimeters were determined after 3 days (Catinot et al., 2015).

\section{Gene Expression}

For gene expression studies, 14-day-old seedlings were transferred to liquid 1/2 MS one night before treatment. Pst DC3000 bacteria were then added to reach a final concentration of $10^{6} \mathrm{cfu} / \mathrm{ml}$ for $3 \mathrm{~h}$. Equivalent volume of $10 \mathrm{mM} \mathrm{MgSO}_{4}$ was used as mock control. Alternatively, flg22 was added to a final concentration of $100 \mathrm{nM}$ for $3 \mathrm{~h}$. Equivalent volume of water was used as mock control. For $B$. cinerea inoculation, spores were added to reach a final concentration of $10^{5}$ spore $/ \mathrm{ml}$ for $24 \mathrm{~h}$. Equivalent volume of $1 / 2$ PDB medium was used as mock control. Samples were harvested and rinsed quickly in $1 / 2 \mathrm{MS}$, blotted dry, and snap frozen in liquid nitrogen. RNA was extracted with TRIzol reagent according to manufacturer's instruction. First strand complementary DNA (cDNA) was synthesized with oligo dT and SuperScript III reverse transcriptase (Invitrogen). Quantitative 
PCR was performed using 2x SYBR green (Bio-Rad) and CFX96 real-time PCR system according to manufacturer's instruction. Primers are listed in Table $\mathbf{S 1}$ and S2.

\section{Chromatin Immunoprecipitation Assays}

Chromatin immunoprecipitation (ChIP) assays were performed according to Lau and Bergmann (2015) with modifications. Briefly, $3 \mathrm{~g}$ of 14-day-old seedlings were harvested in $37 \mathrm{ml}$ of cross-linking buffer [0.4 M sucrose, $10 \mathrm{mM}$ Tris- $\mathrm{HCl}(\mathrm{pH} 8)$, $10 \mathrm{mM} \mathrm{MgCl} 2$, and $1 \%$ (wt/vol) formaldehyde], followed by two rounds of vacuum infiltration, each for $5 \mathrm{~min} ; 2.5 \mathrm{ml}$ of 2 $\mathrm{M}$ glycine was then added, followed by vacuum infiltration for 5 min. Samples were rinsed with water, blotted dry, and grinded to fine powder in liquid nitrogen. The powder samples were resuspended in $40 \mathrm{ml}$ of extraction buffer 1 [0.4 M sucrose, $10 \mathrm{mM}$ Tris- $\mathrm{HCl}$ (pH 8), $10 \mathrm{mM} \mathrm{MgCl}$, and $5 \mathrm{mM} \beta$-mercaptoethanol] and incubated for $10 \mathrm{~min}$ before filtration through two layers of Miracloth (Millipore). The filtrates were centrifuged for $20 \mathrm{~min}$ at 3,000 g at $4^{\circ} \mathrm{C}$ using a swing-bucket rotor. The pellets were then resuspended in $1.3 \mathrm{ml}$ of pre-chilled extraction buffer $2[0.25 \mathrm{M}$ sucrose, $10 \mathrm{mM}$ Tris- $\mathrm{HCl}$ ( $\mathrm{pH}$ 8), $10 \mathrm{mM} \mathrm{MgCl}$, 1\% (vol/vol) Triton X-100, and $5 \mathrm{mM} \beta$-mercaptoethanol] and centrifuged for $10 \mathrm{~min}$ at $12,000 \mathrm{~g}$ at $4^{\circ} \mathrm{C}$. The pellets were then resuspended in $400 \mu \mathrm{l}$ of pre-chilled extraction buffer 3 [1.7 M sucrose, 10 $\mathrm{mM}$ Tris- $\mathrm{HCl}$ ( $\mathrm{pH} 8$ ), $2 \mathrm{mM} \mathrm{MgCl} 2,0.15 \%$ (vol/vol) Triton $\mathrm{X}-100$, and $5 \mathrm{mM} \beta$-mercaptoethanol] and overlaid on another $400 \mu \mathrm{l}$ of pre-chilled extraction buffer 3 in new tubes. Samples were centrifuged for $1 \mathrm{~h}$ at $16,000 \mathrm{~g}$ at $4^{\circ} \mathrm{C}$. The pellets were resuspended in $500 \mu \mathrm{l}$ of nuclei lysis buffer [ $50 \mathrm{mM}$ Tris- $\mathrm{HCl}(\mathrm{pH}$ 8), $10 \mathrm{mM}$ EDTA, and 1\% (wt/vol) SDS] and incubated on ice for $10 \mathrm{~min}$. Finally, samples were sonicated with a $15 \mathrm{sec}$ "ON," $59 \mathrm{sec}$ "OFF" cycle (x 40 cycles) at $40 \%$ output (Misonix 3000), to yield chromatin fragments with 150 base pair average length. Equal volume of the sonicated chromatin solution was set aside as input control.

For characterization of chromatin modification state, the sonicated extract was diluted 10 times with pre-chilled ChIP dilution buffer [16.7 mM Tris- $\mathrm{HCl}(\mathrm{pH} 8), 167 \mathrm{mM} \mathrm{NaCl}, 1.2 \mathrm{mM}$ EDTA, and 1.1\% (vol/vol) Triton X-100], and immunoprecipitated with $10 \mu \mathrm{g}$ of anti-H3K9me2 (Abcam, ab1220) or $10 \mu \mathrm{g}$ of antiH3K4me3 (Millipore, 07-473) antibody for $16 \mathrm{~h}$ At $4^{\circ} \mathrm{C}$. Twenty microliters of pre-washed Magna ChIP Protein A+G Magnetic Beads (Millipore, 16-663) was then added to the chromatinantibody mixture and incubated for $16 \mathrm{~h}$ At $4^{\circ} \mathrm{C}$. For IBM1 targeting, the sonicated extract was diluted 10 times with prechilled ChIP dilution buffer, and immunoprecipitated with $20 \mu \mathrm{l}$ of pre-washed GFP Trap-A beads (Chromotek) for $16 \mathrm{~h}$ At $4^{\circ} \mathrm{C}$.

The magnetic beads were captured with a magnetic stand and washed successively with low-salt wash buffer $[20 \mathrm{mM}$ Tris- $\mathrm{HCl}$ (pH 8), $150 \mathrm{mM} \mathrm{NaCl}, 2 \mathrm{mM}$ EDTA, 0.1\% (wt/vol) SDS, and 1\% (vol/vol) Triton X-100], high-salt wash buffer [20 mM Tris-HCl (pH 8), $500 \mathrm{mM} \mathrm{NaCl}, 2 \mathrm{mM}$ EDTA, 0.1\% (wt/vol) SDS, and 1\% (vol/vol) Triton X-100], LiCl wash buffer [10 mM Tris- $\mathrm{HCl}(\mathrm{pH}$ 8), $250 \mathrm{mM} \mathrm{LiCl}, 1 \mathrm{mM}$ EDTA, 1\% (vol/vol) NP-40, and $0.5 \%$ (wt/vol) sodium deoxycholate] and TE buffer [10 mM Tris- $\mathrm{HCl}$ $(\mathrm{pH} 8)$ and $1 \mathrm{mM}$ EDTA]. Elution and reverse cross-linking was performed in a single step by adding $190 \mu \mathrm{l}$ ChIP elution buffer [0.1 M NaHCO3 and 1\% (wt/vol) SDS] and $8 \mu \mathrm{l}$ of $5 \mathrm{M} \mathrm{NaCl}$, to the input control and immunoprecipitated samples, followed by incubation at $65^{\circ} \mathrm{C}$ for $6 \mathrm{~h}$. Chromatin DNA was purified by ChIP DNA Clean \& Concentrator (Zymo Research) according to manufacturer's instruction.

Quantification of chromatin DNA was performed with realtime quantitative PCR (qPCR) using specific primers listed in Table S3. Relative enrichment was represented by percentage of input, calculated by $2^{-\Delta \mathrm{Ct}}\left(=2^{-[\mathrm{Ct}(\mathrm{ChIP})-\mathrm{Ct}(\text { Input })]}\right)$ (Miura et al., 2009).

\section{Reactive Oxygen Species Burst}

The reactive oxygen species (ROS) assay was carried out as described (Huang et al., 2013). Briefly, nine $0.25 \mathrm{~cm}^{2}$ leaf disks were excised from fully expanded leaves from 5-week-old Arabidopsis plants. The disks were incubated overnight in a 96-well plate with $100 \mu \mathrm{l}$ of sterile water. Water was then replaced by $100 \mu \mathrm{l}$ reaction solution [ $2 \mu \mathrm{l}$ luminol (Sigma), $10 \mu \mathrm{g} / \mathrm{ml}$ horseradish peroxidase (Sigma)], with $100 \mathrm{nM}$ flg22 or water (mock). The plate was analyzed at the indicated intervals for a period of 30 min using a CentroLIApc LB 692 plate luminometer [Berthold Technologies, (Bad Wildbad, Germany)].

\section{Callose Deposition}

Fourteen-day-old seedlings were transferred to $1 / 2 \mathrm{MS}$ liquid medium one night before inoculation with 1 x $10^{6} \mathrm{cfu} / \mathrm{ml}$ Pst DC3000 bacteria for $6 \mathrm{~h}$. Harvested samples were cleared overnight by incubation in $95 \%$ ethanol at room temperature and then washed three times with sterile water. Cleared samples were stained with $0.01 \%$ aniline blue in $0.15 \mathrm{M}$ phosphate buffer, $\mathrm{pH} 9.5$ for $24 \mathrm{~h}$. Callose deposits were visualized under UV illumination using an Olympus BX51 microscope. Quantification of callose deposits was performed on the acquired digital images using ImageJ (https://imagej.nih.gov/ij/).

\section{Accession Numbers}

IBM1 (AT3G07610), PR1 (AT2G14610), PR2 (AT3G57260), FRK1 (AT2G19190), PDF1.2a (AT5G44420).

\section{RESULTS}

\section{IBM1 Positively Regulates Arabidopsis Resistance to Hemi-Biotrophic Bacteria}

In a screen to evaluate whether epigenetic regulators such as IBM1, met1, cmt3, drm1, drm2, drm3, ddm1, and hac1 are involved in Arabidopsis immunity to bacteria, mutants were dip-inoculated with virulent, hemi-biotrophic bacteria Pst DC3000 and disease symptoms were compared to respective wild-type (WT). From this screen, ibm 1 mutant plants were found to develop stronger disease symptoms. IBM1 (At3g07610) encodes a histone H3K9 demethylase with a C-terminal jmjC domain known for histone demethylase activity. In the $i b m 1-3$ and $i b m 1-4$ mutants, the T-DNA is inserted in the sixth and ninth exon, respectively 827 and 2,173 
base pairs downstream of the ATG start site (Figure S1A). Amplification of the genomic DNA and cDNA confirmed that $i b m 1-3$ and $i b m 1-4$ are both homozygous knock-out mutants (Figures S1B, C). To confirm the role of IBM1 in resistance to bacteria, $i b m 1-3$ and $i b m 1-4$ plants were dip-inoculated with Pst DC3000 and disease symptoms and bacterial titers were evaluated at respectively 5 and 3 day-post-inoculation (dpi). Both loss-of-function mutants showed higher bacterial titers (Figure 1A) and increased symptoms (Figure S2) when compared to the Col-0WT control (Figure 1A). Similarly, both ibm1-3 and ibm1-4 mutants demonstrated increased susceptibility after infiltration inoculation with Pst DC3000 (Figure 1B). Furthermore, 3 days after a primary infection with avirulent Pst DC3000 (avrRpt2), three distal leaves of each plant received a second challenge inoculation with virulent Pst DC3000 and bacterial titers were determined 3 days later. As expected, bacterial titers in Col-0 WT preliminary treated with Pst DC3000 (avrRpt2) were significantly reduced when compared to Col-0 WT with mock primary infections (Figure 1C). Bacterial titers in the mutants were also significantly reduced in preliminary Pst DC3000 (avrRpt2)-inoculated plants, while bacteria counts were still significantly higher than the Col-0 WT controls (Figure 1C). This observation implies that IBM1 does not play a critical role in systemic acquired resistance. To further evaluate the role of IBM1 in resistance against deleterious pathogens, $i b m 1-3$ and $i b m 1-4$ plants were

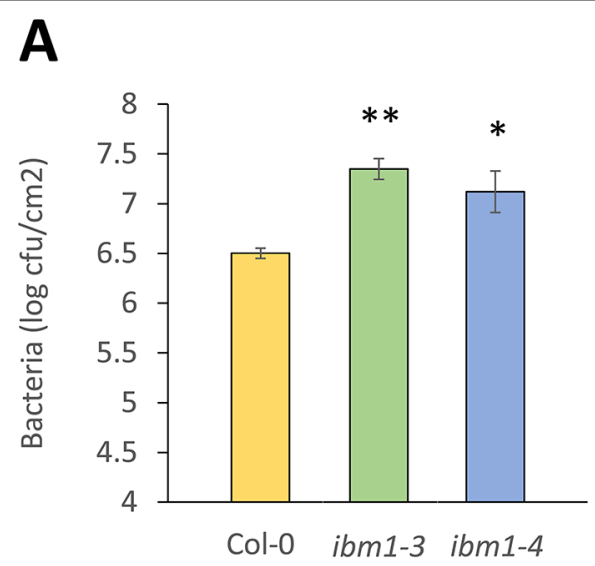

C

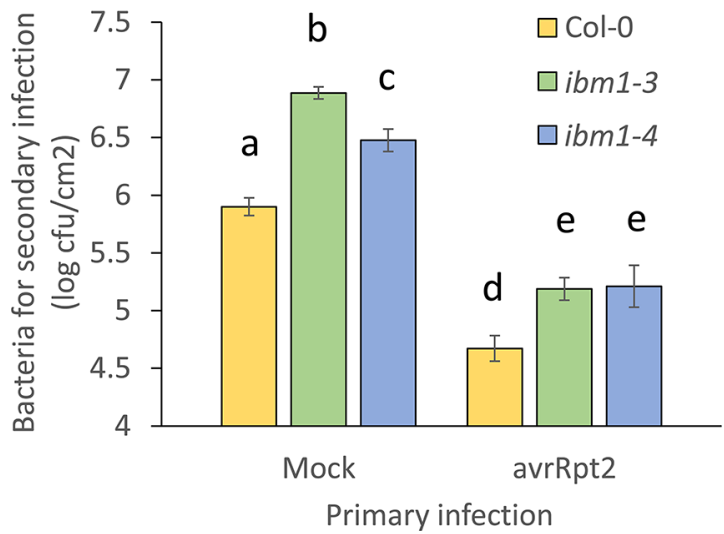

B

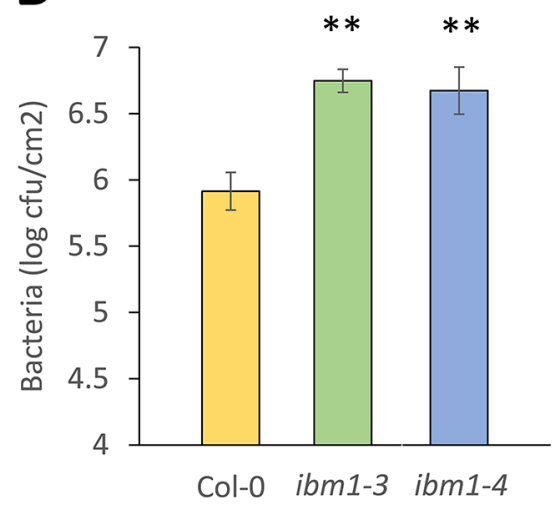

D

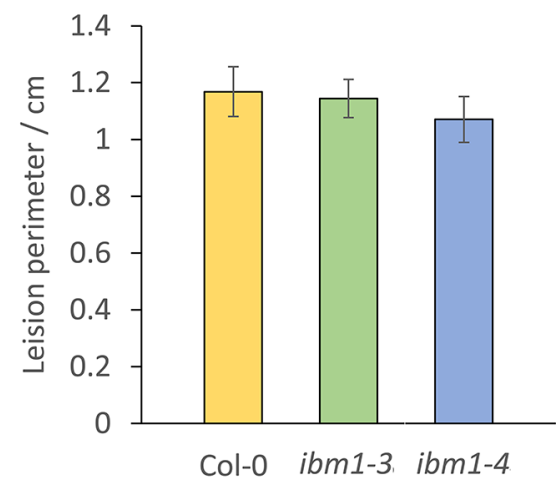

FIGURE 1 | IBM1 positively regulates Arabidopsis resistance to Pst DC3000. (A) The ibm1 mutants are hyper-susceptible to Pst DC3000. Five-week-old plants were dip-inoculated with $10^{6} \mathrm{cfu} / \mathrm{ml}$ Pst DC3000 for $15 \mathrm{~min}$. Bacteria titers were evaluated at $3 \mathrm{dpi}$ in Col-0, ibm1-3, and ibm1-4. Values represent average \pm SEM from three independent experiments each with three plants $(\mathrm{N}=9)$. Asterisks indicate significant differences from the Col-0 wild type $(\mathrm{WT})$ as determined by a paired two-tailed Student's $t$-test $\left({ }^{\star} p<0.05,{ }^{* \star} p<0.01\right)$. (B) Susceptibility to primary Pst DC3000 infiltration inoculation. Three leaves of 5 -week-old plants were infiltrated-inoculated with $10^{5} \mathrm{cfu} / \mathrm{ml}$ Pst DC3000. Bacteria titers were evaluated at $3 \mathrm{dpi}$ in Col-0, ibm1-3, and ibm1-4. Values represent average \pm SEM from three independent experiments each with at least three plants $(\mathrm{N} \geq 9)$. Asterisks indicate significant differences from the Col-0 WT as determined by a paired two-tailed Student's $t$-test $\left({ }^{* \star} \mathrm{p}<0.01\right)$. (C) Susceptibility to secondary Pst DC3000 infiltration inoculation. Three leaves of 5-week-old plants were first infiltrated-inoculated with $10^{7} \mathrm{cfu} / \mathrm{ml}$ of avirulent Pst DC3000 (avrRpt2), or with $10 \mathrm{mM} \mathrm{MgSO}_{4}$ as mock control. After 3 days, three other leaves were infiltrated-inoculated with $10^{5} \mathrm{cfu} / \mathrm{ml}$ Pst DC3000. Bacteria titers were evaluated at 3 dpi in Col-0, ibm 1-3, and ibm1-4. Values represent average \pm SEM from three independent experiments each with three plants $(N=9)$. Letters denote significant differences based on a one-way ANOVA with post hoc Tukey honestly significant difference ( $p<0.05)$. (D) Susceptibility to Botrytis cinerea. Five-week-old plants were droplet-inoculated with B. cinerea (droplets of $10 \mu \mathrm{l}$ with $10^{5} \mathrm{spores} / \mathrm{ml}$ ) in $1 / 2$ potato dextrose agar medium. Lesion perimeters were evaluated at $3 \mathrm{dpi}$ in Col-0, ibm 1-3, and ibm 1-4. Values represent average \pm SEM from three independent experiments each with at least three plants $(N \geq 9)$. No significant differences were observed as determined by a paired two-tailed Student's $t$-test $(p<0.05)$. 
droplet-inoculated with $B$. cinerea, a necrotrophic fungal pathogen (Zimmerli et al., 2001). When lesion perimeters and symptoms were determined at $3 \mathrm{dpi}$, no significant differences were observed between ibm 1 mutants and the Col-0 WT (Figure 1D and Figure S2). Taken together, these data suggest that IBM1 is required for basal level of resistance against hemibiotrophic bacteria but not for systemic acquired resistance, nor resistance against necrotrophic pathogens.

\section{Up-Regulation of Defense Marker Genes Is Compromised in ibm1 Mutants}

IBM1 controls flowering, seed and shoot development (Saze et al., 2008). However, the role of IBM1 in biotic stress is largely unknown. To test whether IBM1 is critical for the regulation of defense related genes, we analyzed the expression of $P R 1, P R 2$, and the PTI marker FRK1 $3 \mathrm{~h}$ after inoculation with Pst DC3000. As expected, $P R 1, P R 2$, and FRK1 were strongly up-regulated in Col-0 WT controls after Pst DC3000 inoculation (Figure 2A). By contrast, up-regulation of $P R 1, P R 2$, and FRK1 was abolished in $i b m 1$ mutants (Figure 2A). These data are consistent with the observed hyper-susceptibility phenotype of $i b m 1$ mutants (Figures 1A, B). Similarly, treatment with flg22, a 22-amino acid peptide derived from the terminus of the PAMP flagellin (Gomez-Gomez and Boller, 2000), induced PR1, PR2, and FRK1 expression in Col-0 WT but not in the ibm 1 mutants (Figure 2B). On the other hand, upon inoculation with $B$. cinerea spores, the expression of PDF1.2a, a known marker gene for necrotrophic attack (Thomma et al., 1998; Zimmerli et al., 2001), was not affected in the $i b m 1$ mutants (Figure S3). Notably, significant up-regulation of IBM1 gene expression was not observed upon Pst DC3000 inoculation or after flg22 treatment (Figure S4). Together these data suggest that IBM1 is required for basal defense response activation without being induced by pathogen elicitation.

\section{IBM1 Controls the Chromatin Modification States At PR1, PR2, and FRK1 Loci}

IBM1 preferentially demethylates $\mathrm{H} 3 \mathrm{~K} 9$ at low-copy loci to protect transcribed genes from DNA methylation at CHG sites (Miura et al., 2009). To address whether IBM1 regulates the expression of PR1, PR2, and FRK1 by modulating histone methylation of these loci, we applied the ChIP assay followed by qPCR quantification and used a panel of primers spanning across these defense-related loci (Figure S5). Higher levels of H3K9me2, an inactivation mark, in the ibm1-4 mutant for PR1, PR2, and FRK1 were observed (Figure 3A). In addition, the levels of $\mathrm{H} 3 \mathrm{~K} 4 \mathrm{me} 3$, an activation mark (Fan et al., 2012), were significantly reduced in the $i b m 1$ mutant for PR1, PR2, and FRK1 (Figure 3B). Together, these data are consistent with the observed defective up-regulation of these defense genes upon bacterial attack. On the other hand, PDF1.2a showed no significant difference for both $\mathrm{H} 3 \mathrm{~K} 9 \mathrm{me} 2$ and H3K4me3 levels (Figure S6). Therefore, IBM1 is required for the suppression of the repressive histone mark H3K9me2 and the accumulation of the activation histone mark $\mathrm{H} 3 \mathrm{~K} 4 \mathrm{me} 3$ at $P R 1$, PR2, and FRK1.
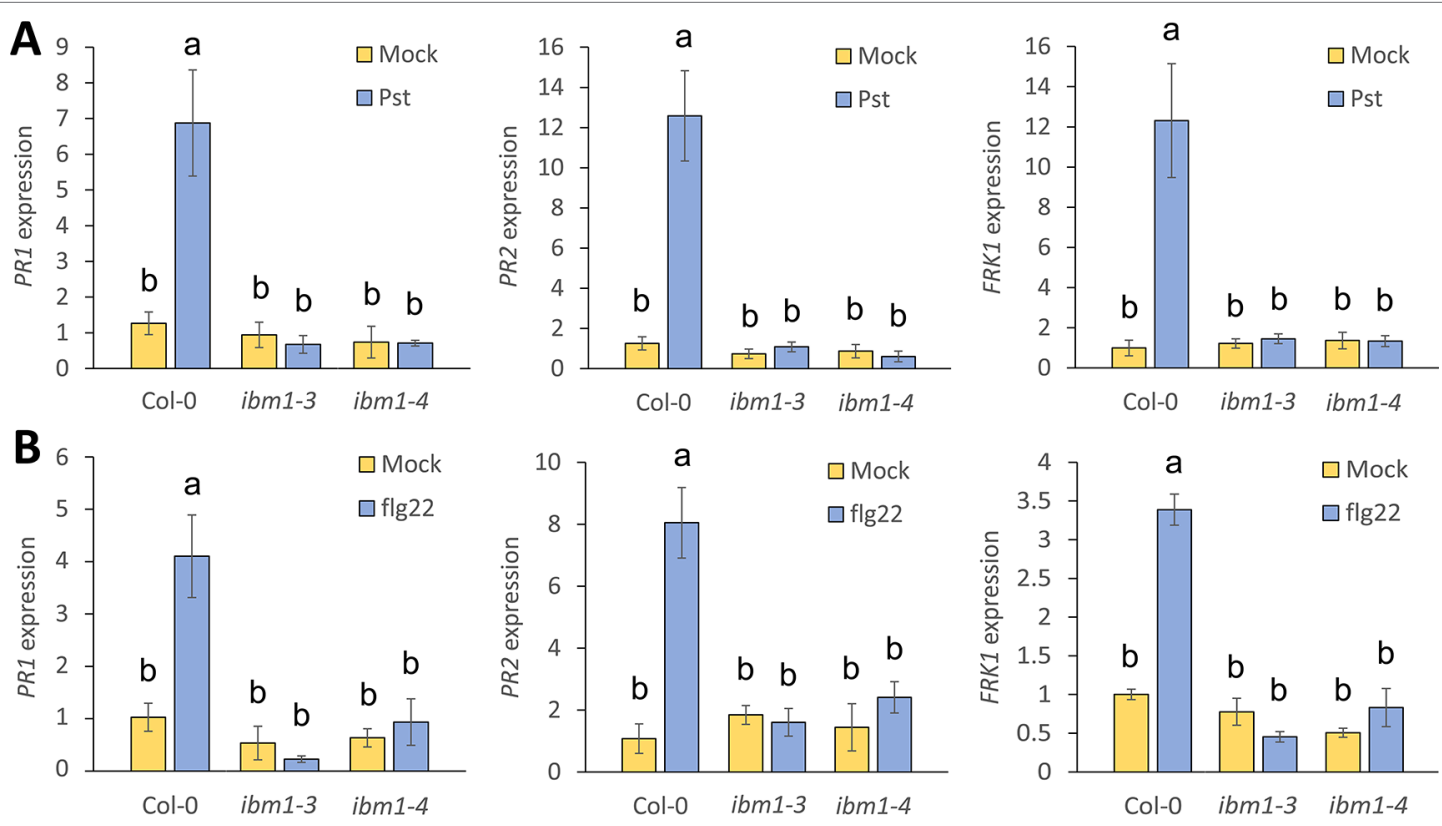

FIGURE 2 | Up-regulation of immunity marker genes is compromised in ibm1 mutants. (A) Up-regulation of defense marker genes after Pst DC3000 inoculation. Fourteen-day-old seedlings were floated in liquid 1/2 Murashige and Skoog (MS) for one night before inoculation with $10^{6} \mathrm{cfu} / \mathrm{ml}$ Pst DC3000 for $3 \mathrm{~h}$. Equivalent volume of $10 \mathrm{mM} \mathrm{MgSO}_{4}$ was used as mock control. Transcript levels of PR1, PR2, and FRK1 were determined by quantitative real-time PCR and normalized to UBQ10 (Col-0 mock as defined value of 1 ). Values represent average \pm SEM from three independent experiments each with three technical repeats $(\mathrm{N}=9)$. Letters denote significant differences based on a one-way ANOVA with post hoc Tukey honestly significant difference $(p<0.05)$. (B) Up-regulation of defense marker genes after flg22 treatment. Fourteen-day-old seedlings were floated in liquid 1/2 MS for one night before treatment with $100 \mathrm{nM}$ flg22 for $3 \mathrm{~h}$. Equivalent volume of water was used as mock control. Gene expression of $P R 1, P R 2$, and FRK1 were evaluated and analyzed as in A. 

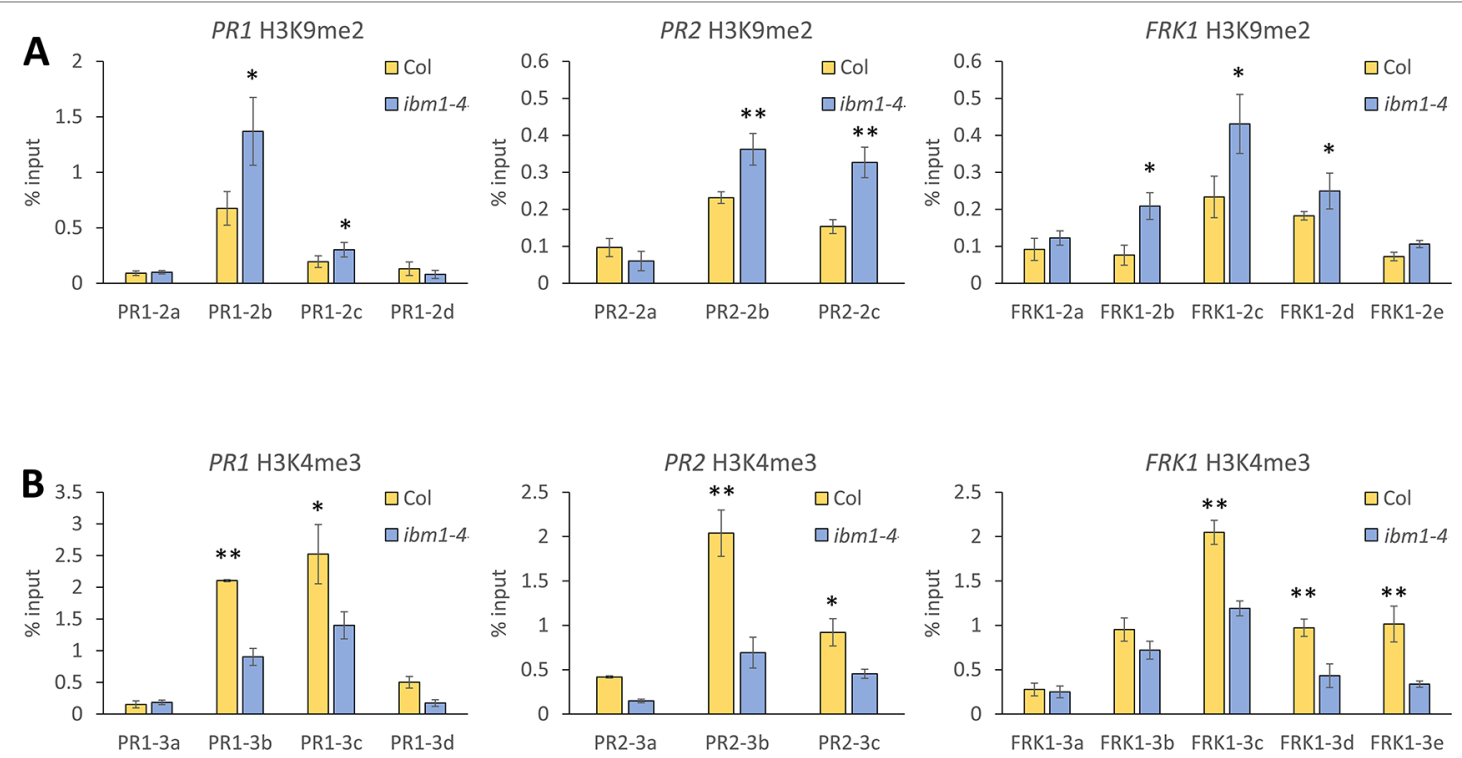

FIGURE 3 | IBM1 modulates the chromatin state of defense marker genes. (A) Detection of H3K9me2 levels. Tissue of 14-day-old seedlings were pooled and chromatin immunoprecipitation was carried out using anti-H3K9me2 antibody for Col-0 and ibm1-4. The associated chromatin was quantified by quantitative PCR with primers spanning across PR1, PR2, and FRK1. Relative enrichments were calculated as percentage of input. Values represent average \pm SD from four technical repeats $(\mathrm{N}=4)$. The experiment was repeated twice with similar patterns and one representative repeat is shown. Asterisks indicate significant differences from respective Col-0 wild type controls as determined by a paired two-tailed Student's $t$-test $\left({ }^{*} \mathrm{p}<0.05\right.$, $\left.{ }^{\star *} \mathrm{p}<0.01\right)$. (B) Detection of H3K4me3 levels for PR1, PR2, and FRK1 were evaluated and analyzed as in A with anti-H3K4me3 antibody.

\section{IBM1 Associates Directly With PR1, PR2, and FRK1 Chromatin}

To investigate whether IBM1 directly associates with the chromatin of $P R 1, P R 2$, and FRK1, ChIP assays were used with transgenic plants expressing ProIBM1::IBM1-GFP in the ibm1-4 mutant background. Chromatin associated with IBM1 was immunoprecipitated using anti-green fluorescent protein (GFP) magnetic beads and quantified by qPCR. Significant enrichments of PR1, PR2, and FRK1 DNA fragments in IBM1-GFP transgenic plants were observed when compared to GFP only controls (Figure 4). On the other hand, significant enrichments of PDF1.2a DNA fragments in IBM1-GFP transgenic plants were not observed (Figure S7). Taken together, our data suggest that IBM1 associates directly with the gene body of $P R 1, P R 2$, and FRK1. Thus, IBM1 may modulate the chromatin modification state of these loci. Notably, $P R 1, P R 2$, and FRK1 are hyper-methylated in $i b m 1$ mutants and hence up-regulation upon bacterial infection is hindered, leading to hyper-susceptibility to Pst bacteria.

\section{IBM1 Does Not Play an Important Role in Apoplastic Pattern-Triggered Immunity}

Since FRK1 is an important marker for PTI (Gomez-Gomez et al., 1999; Xiao et al., 2007), we also investigated the potential role of IBM1 in other apoplastic PTI responses. As an early PTI response, we first analyzed the production of ROS after treatment with $100 \mathrm{nM}$ flg22. No significant differences between the Col-0 WT, ibm1-3, and ibm1-4 were observed (Figure 5A). Pathogen- or PAMP-mediated callose deposition is considered an important late PTI response (Zipfel and Robatzek, 2010;
Yeh et al., 2016). Callose deposition was thus evaluated after inoculation with Pst DC3000 bacteria. Aniline blue staining and image analysis revealed that the increase in callose deposition in the Col-0 WT control, ibm1-3, and ibm1-4 mutants were at similar levels (Figure 5B). Taken together, our data suggest that IBM1 mainly plays a role in regulating defense gene expression and is not critical in other apoplastic PTI responses.

\section{Repression of ibm1-Induced Immunity Defects}

$I b m 1$ mutants display a number of developmental defects due to ectopic H3K9me2 and/or CHG methylation in genic regions (Rigal et al., 2012). Mutations in kyp and ldl2 suppress $i b m 1$ mutants developmental abnormalities (Rigal et al., 2012). To address whether $i b m 1$-induced immunity defect can also be rescued by mutations in kyp and ldl2, kypibml, and ldl2ibm 1 double mutants were challenged with Pst DC3000. After infiltration inoculation, kypibm 1 and $l d l 2 i b m 1$ harbored bacterial titers similar to ibm1-4 (Figure S8), indicating that these double mutants are hyper-susceptible to Pst DC3000. These data suggest that in contrary to developmental defects, mutations in kyp and $l d l 2$ cannot suppress ibml defective immunity to Pst DC3000.

\section{DISCUSSION}

In this work, we provide physiological and molecular evidences to show that the epigenetic regulator IBM1 plays a key role in maintaining Arabidopsis basal immunity to bacteria. More specifically, the role of IBM1 on the expression of defense genes upon bacteria infection and PAMP perception is highlighted. 


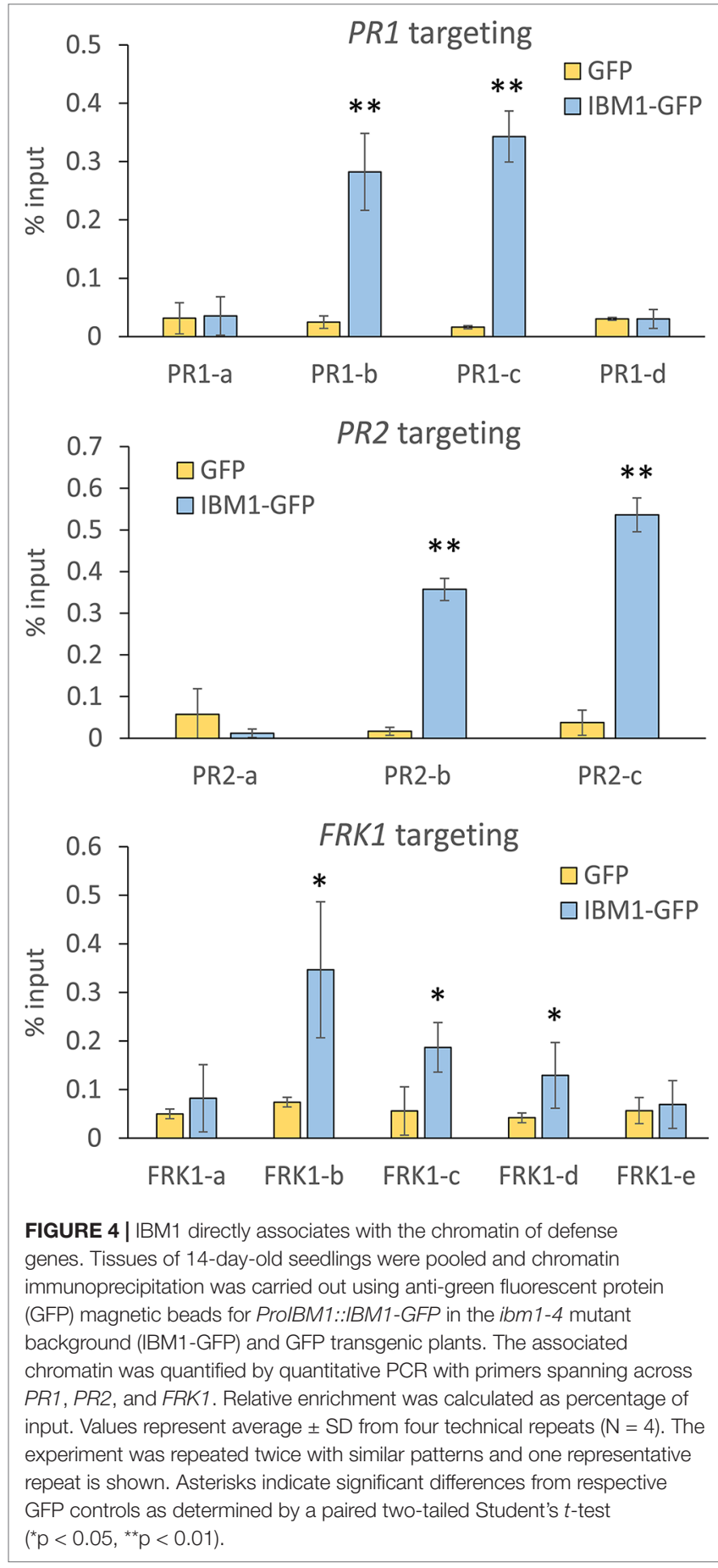

\section{IBM1 Positively Regulates Arabidopsis Resistance to Pst DC3000 Bacteria}

Loss of IBM1 increased plant susceptibility to the bacterial pathogen Pst DC3000. In addition, upon bacteria inoculation or treatment with the PAMP flg22, ibm 1 mutants failed to show up-regulation of a subset of defense genes, including $P R 1, P R 2$, and FRK1. DNA methylation at CG or non-CG sites, and histone modification at $\mathrm{H} 3 \mathrm{~K} 4, \mathrm{H} 3 \mathrm{~K} 9, \mathrm{H} 3 \mathrm{~K} 27$, and $\mathrm{H} 3 \mathrm{~K} 36$ have been associated with plant defense (Berr et al., 2010; Dowen et al., 2012;
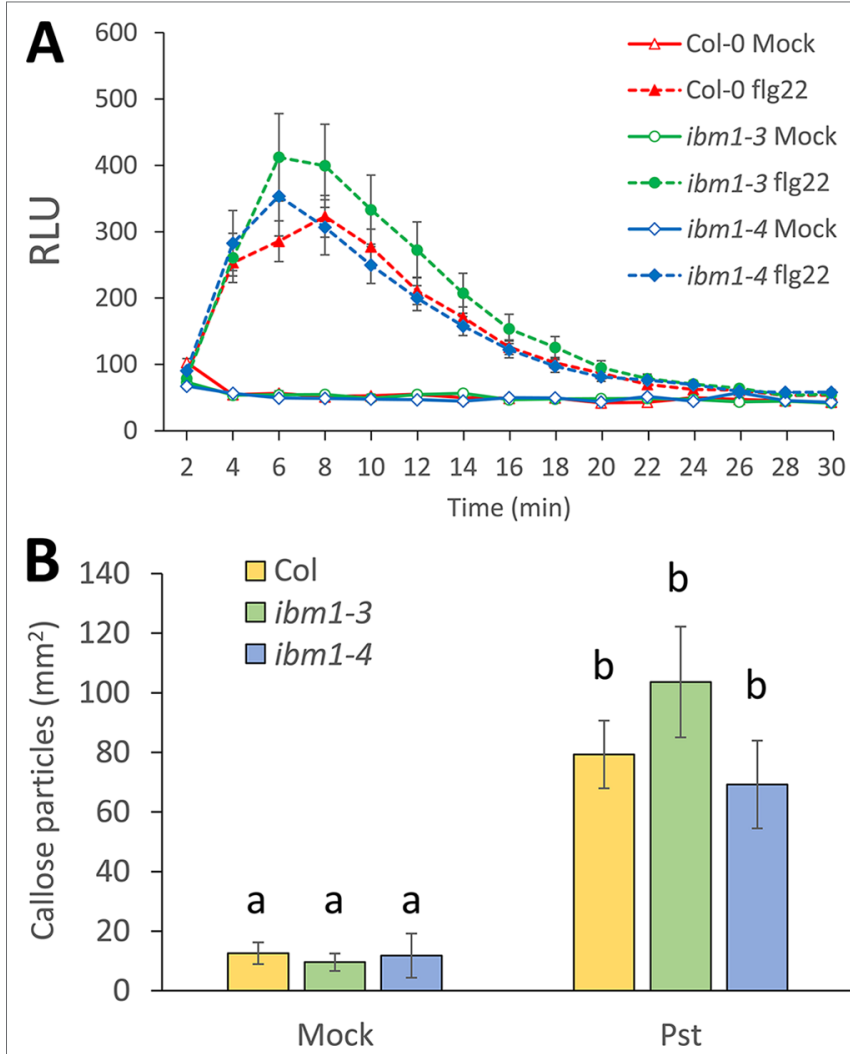

FIGURE 5| The role of IBM1 in apoplastic PTI. (A) Reactive oxygen species production. Leaf disks from 5-week-old plants were treated with $100 \mathrm{nM}$ flg22 or water (mock). Relative light units (RLUs) were evaluated at the indicated time points. Values represent average \pm SEM from three independent experiments, each consisting of six leaf disks $(N=18)$. No significant differences to the Col-0 wild type (WT) were observed when analyzed with a paired two-tailed Student's t-test $(p<0.05)$. (B) Callose deposition. Fourteen-day-old seedlings were floated in liquid 1/2 Murashige and Skoog for one night before treatment with $10^{6} \mathrm{cfu} / \mathrm{ml}$ Pst DC3000 for $6 \mathrm{~h}$. Equivalent volumes of $10 \mathrm{mM} \mathrm{MgSO}_{4}$ were used for mock controls. Values represent average \pm SEM from three independent experiments, each consisting of at least three seedlings ( $N=9$ ). No significant differences to respective Col-0 WT were observed when analyzed with a one-way ANOVA with post hoc Tukey honestly significant difference $(p<0.05)$.

Li et al., 2013; Singh et al., 2014). For example, mutants defective in DNA methylation such as met 1-3 and $d d c$ are highly resistant to bacteria, and harbor a mis-regulated Pst-induced transcriptional regulatory network (Dowen et al., 2012). Notably, PR1 expression levels are significantly higher in both met1-3 and $d d c$ mutants than in WT controls after Pst infection (Dowen et al., 2012). The PR1 locus is not a direct target for DNA methylation, so the observed altered expression is believed to be an indirect consequence of other epigenetic modification further upstream (Dowen et al., 2012). In this study however, the observed reduced $\mathrm{H} 3 \mathrm{~K} 4 \mathrm{me} 3$ and increased $\mathrm{H} 3 \mathrm{~K} 9 \mathrm{me} 2$ in ibm 1-4 mutant may be the primary cause for the failed up-regulation of defense genes and increased susceptibility.

SDG8, a SET DOMAIN GROUP8 methyltransferase mediates H3K38 dependent defense gene expression against necrotrophic fungal pathogens (Berr et al., 2010). To test whether IBM1 also 
plays a role in Arabidopsis immunity against fungal pathogens, $i b m 1$ mutants were challenged with the necrotrophic fungal pathogen B. cinerea. By contrast to infection by Pst DC3000 bacteria, $i b m 1$ mutants showed WT resistance to $B$. cinerea. Consistently, the up-regulation of PDF1.2a, a critical defense gene activated upon infection with necrotrophs (Berr et al., 2010), was not affected in the $i b m 1$ mutants after inoculation with $B$. cinerea spores. Therefore, IBM1 may only play a role in regulating resistance and defense gene expression under bacterial infection.

\section{IBM1 Is Not Critical for Apoplastic Pattern-Triggered Immunity Responses}

Apoplastic PTI is a complex set of responses crucial for resisting pathogen attack (Boller and Felix, 2009). The first line of defense involves the recognition of PAMPs by cell surface pattern recognition receptors (PRRs) such as FLS2 and EF-TU Receptor (EFR) that recognize the conserved N-terminus of bacteria flagellin (Gomez-Gomez and Boller, 2000), and the bacterial protein elongation factor-Tu (Kunze et al., 2004), respectively. Other players, including malectin-like/leucine rich repeat receptor-like kinases (Yeh et al., 2016; Stegmann et al., 2017), lectin receptor kinases (Bouwmeester and Govers, 2009; Bouwmeester et al., 2011; Desclos-Theveniau et al., 2012; Singh et al., 2012; Huang et al., 2014) and cysteine-rich receptor-like kinases (Bourdais et al., 2015; Yeh et al., 2015), among others, act as agonists or antagonists of the PRR complexes to fine tune PTI activation and silencing. Recognition of PAMPs by PRRs is usually followed by the accumulation of ROS and callose (Zipfel and Robatzek, 2010). So far, the characterization of epigenetic regulators in relation to plant immunity mainly focuses on the correlation between the disease phenotype, defense gene expression, and DNA methylation/histone modification patterns (Espinas et al., 2016; Li et al., 2016). Investigation of other aspects of the PTI response is largely deficient. Yet, HAC1 was reported to modulate some aspects of PTI, including deposition of callose (Singh et al., 2014). In this report, ROS burst and callose deposition were selected as PTI outcomes not linked to gene expression to further investigate the role of IBM1 in PTI. No significant differences between $i b m 1$ mutants and Col-0 WT in ROS accumulation and callose deposition upon bacterial inoculation and after PAMP treatment were observed. These data suggest that IBM1 mainly controls histone methylation patterns at selected loci, and hence the expression of specific defense genes, but is likely not a regulator of other immunity responses.

\section{IBM1 as a Chromatin Modification Regulator in Plant-Microbe Interaction}

Depending on their specific target loci, posttranslational histone modifications and DNA methylation can play both positive and negative roles in regulating gene transcription (Zhu, 2009). Notably, SDG27 positively regulates H3K4me3 patterns at the key defense related locus WRKY70, but not at PR1 nor at THI2.1 (Alvarez-Venegas et al., 2006). Similarly, the sdg8 mutant is hyper-susceptible to fungal pathogens due to a loss of H3K36me3-mediated activation of PDF2.1, VSP2, ERF1, and MYC2 (Berr et al., 2010). By contrast, JMJ705 promotes rice resistance against bacterial blight via reduction of $\mathrm{H} 3 \mathrm{~K} 27 \mathrm{me} 3$ levels at PR5 and PR10 (Li et al., 2013). In this report, we show that IBM1 is required for Arabidopsis full resistance to Pst DC3000 infection. The defective defense response in $i b m 1$ mutants is correlated with a loss of up-regulation of defense marker genes such as PR1, PR2, and FRK1. In addition, $i b m 1$ mutants harbored an increased accumulation of the inactivation histone mark $\mathrm{H} 3 \mathrm{~K} 9 \mathrm{me} 2$ and a reduction of the activation mark $\mathrm{H} 3 \mathrm{~K} 4 \mathrm{me} 3$ at these defense loci. Unlike SDG27, which maintains $\mathrm{H} 3 \mathrm{~K} 4 \mathrm{me} 3$ at the promoter of WRKY70 (Alvarez-Venegas et al., 2007), IBM1 maintained H3K4me3 at the gene body of $P R 1, P R 2$, and FRK1. Although mutations in epigenetic regulators such as $k y p$ and $l d l 2$ are known to suppress the epigenetic and developmental defect of $i b m 1$ mutants (Rigal et al., 2012), mutations in kyp and ldl2 could not rescue the $i b m 1$-induced immunity defect (Figure S8). KYP and LDL2 act on histone methylation at chromatin level (Saze et al., 2012; Du et al., 2014; Inagaki et al., 2017), and apparently the absence of functional KYP and LDL2 cannot restore full resistance in $i b m 1$. Therefore, like JMJ705 in rice ( $\mathrm{Li}$ et al., 2013), IBM1 may be critical to Arabidopsis resistance to Pst DC3000 via a direct regulatory role at defense genes.

\section{CONCLUDING REMARKS}

This work shows that IBM1 is required for Arabidopsis full resistance to Pst DC3000 infection. IBM1 did not play an important role in systemic acquired resistance, nor resistance to necrotrophic pathogens such as $B$. cinerea. The defective defense response in $i b m 1$ mutants may be primarily due to the loss of up-regulation of defense genes, including $P R 1, P R 2$, and FRK1 upon bacterial infection. The accumulation of the inactivation histone mark $\mathrm{H} 3 \mathrm{~K} 9 \mathrm{me} 2$ and the reduction of the activation mark $\mathrm{H} 3 \mathrm{~K} 4 \mathrm{me} 3$ at these defense loci may explain the defective up-regulation of these defense genes. This study also demonstrated the direct association of IBM1 with the chromatin of PR1, PR2, and FRK1. In addition, analyses of ROS production and callose deposition suggest that IBM1 does not play an important role in other PTI responses. Taken together, our results highlight the importance of IBM1 in plant immunity through the control of defense genes via histone modification.

\section{DATA AVAILABILITY STATEMENT}

All datasets generated for this study are included in the article/ Supplementary Material.

\section{AUTHOR CONTRIBUTIONS}

CC and LZ designed the study and wrote the manuscript. CC performed the experiments. 


\section{FUNDING}

This work was supported by the Ministry of Science and Technology of Taiwan, grants 102-2628-B-002-011-MY3 and 105-2311-B-002-032-MY3 (to LZ).

\section{ACKNOWLEDGMENTS}

We thank ABRC for providing seeds, and B.N. Kunkel and C.Y. Chen for Pst bacteria and B. cinerea, respectively. We also

\section{REFERENCES}

Alvarez, M. E., Nota, F., and Cambiagno, D. A. (2010). Epigenetic control of plant immunity.Mol.PlantPathol.11,563-576.doi: 10.1111/j.1364-3703.2010.00621.x

Alvarez-Venegas, R., Sadder, M., Hlavacka, A., Baluska, F., Xia, Y. N., Lu, G. Q., et al. (2006). The Arabidopsis homolog of trithorax, ATX1, binds phosphatidylinositol 5-phosphate, and the two regulate a common set of target genes. Proc. Natl. Acad. Sci. U.S.A. 103, 6049-6054. doi: 10.1073/pnas.0600944103

Alvarez-Venegas, R., Al Abdallat, A., Guo, M., Alfano, J. R., and Avramova, Z. (2007). Epigenetic control of a transcription factor at the cross section of two antagonistic pathways. Epigenetics 2, 106-113. doi: 10.4161/epi.2.2.4404

Bari, R., and Jones, J. (2009). Role of plant hormones in plant defence responses. Plant Mol. Biol. 69, 473-488. doi: 10.1007/s11103-008-9435-0

Berr, A., McCallum, E. J., Alioua, A., Heintz, D., Heitz, T., and Shen, W. H. (2010). Arabidopsis histone Methyltransferase set domain group8 mediates induction of the jasmonate/ethylene pathway genes in plant defense response to necrotrophic fungi. Plant Physiol. 154, 1403-1414. doi: 10.1104/pp.110.161497

Boller, T., and Felix, G. (2009). A renaissance of elicitors: perception of microbeassociated molecular patterns and danger signals by pattern-recognition receptors. Annu. Rev. Plant Biol. 60, 379-406. doi: 10.1146/annurev. arplant.57.032905.105346

Bourdais, G., Burdiak, P., Gauthier, A., Nitsch, L., Salojärvi, J., Rayapuram, C., et al. (2015). Large-Scale Phenomics Identifies Primary and Fine-Tuning Roles for CRKs in Responses Related to Oxidative Stress. PloS Genet. 11, e1005373. doi: 10.1371/journal.pgen.1005373

Bouwmeester, K., and Govers, F. (2009). Arabidopsis L-type lectin receptor kinases: phylogeny, classification, and expression profiles. J. Exp. Bot. 60, 43834396. doi: 10.1093/jxb/erp277

Bouwmeester, K., De Sain, M., Weide, R., Gouget, A., Klamer, S., Canut, H., et al. (2011). The Lectin Receptor Kinase LecRK-I.9 is a novel phytophthora resistance component and a potential host target for a RXLR effector. PloS Pathog. 7, e1001327. doi: 10.1371/journal.ppat.1001327

Catinot, J., Huang, J. B., Huang, P. Y., Tseng, M. Y., Chen, Y. L., Gu, S. Y., et al. (2015). ETHYLENE RESPONSE FACTOR 96 positively regulates Arabidopsis resistance to necrotrophic pathogens by direct binding to GCC elements of jasmonate - and ethylene-responsive defence genes. Plant Cell Environ. 38, 2721-2734. doi: 10.1111/pce.12583

Desclos-Theveniau, M., Arnaud, D., Huang, T. Y., Lin, G. J. C., Chen, W. Y., Lin, Y. C., et al. (2012). The arabidopsis lectin receptor kinase LecRK-V.5 Represses stomatal immunity induced by pseudomonas syringae pv. tomato DC3000. PloS Pathog. 8, e1002513. doi: 10.1371/journal.ppat.1002513

Dowen, R. H., Pelizzola, M., Schmitz, R. J., Lister, R., Dowen, J. M., Nery, J. R., et al. (2012). Widespread dynamic DNA methylation in response to biotic stress. Proc. Natl. Acad. Sci. U.S.A. 109, E2183-E2191. doi: 10.1073/pnas.1209329109

Du, J., Johnson, L.M., Groth, M., Feng, S., Hale, C.J., Li, S., et al. (2014). Mechanism of DNA methylation-directed histone methylation by KRYPTONITE. Mol. Cell $55,495-504$

Espinas, N. A., Saze, H., and Saijo, Y. (2016). Epigenetic Control of Defense Signaling and Priming in Plants. Front. Plant Sci. 7, 1201. doi: 10.3389/ fpls.2016.01201

Fan, D., Dai, Y., Wang, X., Wang, Z., He, H., Yang, H., et al. (2012). IBM1, a JmjC domain-containing histone demethylase, is involved in the regulation of RNAdirected DNA methylation through the epigenetic control of RDR2 and DCL3 thank the Technology Commons (TechComm), College of Life Science, National Taiwan University for providing qRTPCR equipment.

\section{SUPPLEMENTARY MATERIAL}

The Supplementary Material for this article can be found online at: https://www.frontiersin.org/articles/10.3389/fpls.2019.01587/ full\#supplementary-material

expression in Arabidopsis. Nucleic Acids Res. 40, 8905-8916. doi: 10.1093/nar/ gks647

Fu, Z. Q., and Dong, X. N. (2013). Systemic Acquired Resistance: Turning Local Infection into Global Defense. Annu. Rev. Plant Biol. 64, 839-863. doi: 10.1146/ annurev-arplant-042811-105606 In SS Merchant, ed.

Gomez-Gomez, L., and Boller, T. (2000). FLS2: an LRR receptor-like kinase involved in the perception of the bacterial elicitor flagellin in Arabidopsis. Mol. Cell 5, 1003-1011. doi: 10.1016/S1097-2765(00)80265-8

Gomez-Gomez, L., Felix, G., and Boller, T. (1999). A single locus determines sensitivity to bacterial flagellin in Arabidopsis thaliana. Plant J. 18, 277-284. doi: 10.1046/j.1365-313X.1999.00451.X

Hou, Y. X., Wang, L. Y., Wang, L., Liu, L. M., Li, L., Sun, L., et al. (2015). JMJ704 positively regulates rice defense response against Xanthomonas oryzae pv. oryzae infection via reducing $\mathrm{H} 3 \mathrm{~K} 4 \mathrm{me} 2 / 3$ associated with negative disease resistance regulators. BMC Plant Biol. 15, 286. doi: 10.1186/ s12870-015-0674-3

Huang, P. Y., and Zimmerli, L. (2014). Enhancing crop innate immunity: new promising trends. Front. Plant Sci. 5, 624. doi: 10.3389/fpls.2014.00624

Huang, T. Y., Desclos-Theveniau, M., Chien, C. T., and Zimmerli, L. (2013). Arabidopsis thaliana transgenics overexpressing IBR3 show enhanced susceptibility to the bacterium Pseudomonas syringae. Plant Biol. 15, 832-840. doi: 10.1111/j.1438-8677.2012.00685.x

Huang, P. Y., Yeh, Y. H., Liu, A. C., Cheng, C. P., and Zimmerli, L. (2014). The Arabidopsis LecRK-VI.2 associates with the pattern-recognition receptor FLS2 and primes Nicotiana benthamiana pattern-triggered immunity. Plant J. 79, 243-255. doi: 10.1111/tpj.12557

Inagaki, S., Miura-Kamio, A., Nakamura, Y., Lu, F. L., Cui, X., Cao, X. F., et al. (2010). Autocatalytic differentiation of epigenetic modifications within the Arabidopsis genome. EMBO J. 29, 3496-3506. doi: 10.1038/emboj.2010.227

Inagaki, S., Takahashi, M., Hosaka, A., Ito, T., Toyoda, A., Fujiyama, A., et al. (2017). Gene-body chromatin modification dynamics mediate epigenome differentiation in Arabidopsis. EMBO J. 36, 970-980.

Katagiri, F., Thilmony, R., and He, S. Y. (2002). The Arabidopsis ThalianaPseudomonas Syringae Interaction. Arabidopsis Book / Am. Soc. Plant Biol. 1, e0039. doi: 10.1199/tab.0039

Koornneef, A., and Pieterse, C. M. J. (2008). Cross talk in defense signaling. Plant Physiol. 146, 839-844. doi: 10.1104/pp.107.112029

Kunze, G., Zipfel, C., Robatzek, S., Niehaus, K., Boller, T., and Felix, G. (2004). The $\mathrm{N}$ terminus of bacterial elongation factor Tu elicits innate immunity in Arabidopsis plants. Plant Cell 16, 3496-3507. doi: 10.1105/tpc.104.026765

Lau, O. S., and Bergmann, D. C. (2015). MOBE-ChIP: a large-scale chromatin immunoprecipitation assay for cell type-specific studies. Plant J. 84, 443-450. doi: $10.1111 /$ tpj. 13010

Li, T. T., Chen, X. S., Zhong, X. C., Zhao, Y., Liu, X. Y., Zhou, S. L., et al. (2013). Jumonji C Domain Protein JMJ705-Mediated removal of histone H3 Lysine 27 Trimethylation is involved in defense-related gene activation in rice. Plant Cell 25, 4725-4736. doi: 10.1105/tpc.113.118802

Li, B., Meng, X. Z., Shan, L. B., and He, P. (2016). Transcriptional Regulation of Pattern-Triggered Immunity in Plants. Cell Host. Microbe 19, 641-650. doi: 10.1016/j.chom.2016.04.011

Luna, E., Bruce, T. J. A., Roberts, M. R., Flors, V., and Ton, J. (2012). NextGeneration Systemic Acquired Resistance. Plant Physiol. 158, 844-853. doi: $10.1104 /$ pp. 111.187468 
Miura, A., Nakamura, M., Inagaki, S., Kobayashi, A., Saze, H., and Kakutani, T. (2009). An Arabidopsis jmjC domain protein protects transcribed genes from DNA methylation at CHG sites. EMBO J. 28, 1078-1086. doi: 10.1038/ emboj.2009.59

Rigal, M., Kevei, Z., Pélissier, T., and Mathieu, O. (2012). DNA methylation in an intron of the IBM1 histone demethylase gene stabilizes chromatin modification patterns. EMBO J. 31, 2981-2993. doi: 10.1038/emboj.2012.141

Saze, H., Shiraishi, A., Miura, A., and Kakutani, T. (2008). Control of genic DNA methylation by a jmjC domain - Containing protein in Arabidopsis thaliana. Science 319, 462-465. doi: 10.1126/science.1150987

Saze, H., Tsugane, K., Kanno, T., and Nishimura, T. (2012). DNA methylation in plants: relationship to small RNAs and histone modifications, and functions in transposon inactivation. Plant Cell Physiol. 53, 766-784.

Singh, P., Kuo, Y. C., Mishra, S., Tsai, C. H., Chien, C. C., Chen, C. W., et al. (2012). The Lectin Receptor Kinase-VI.2 Is Required for Priming and Positively Regulates Arabidopsis Pattern-Triggered Immunity. Plant Cell 24, 1256-1270. doi: 10.1105/tpc.112.095778

Singh, P., Yekondi, S., Chen, P.-W., Tsai, C.-H., Yu, C.-W., Wu, K., et al. (2014). Environmental history modulates arabidopsis pattern-triggered immunity in a histone acetyltransferase1-dependent manner. Plant Cell 26, 2676-2688. doi: $10.1105 /$ tpc.114.123356

Stegmann, M., Monaghan, J., Smakowska-Luzan, E., Rovenich, H., Lehner, A., Holton, N., et al. (2017). The receptor kinase FER is a RALF-regulated scaffold controlling plant immune signaling. Science 355, 287-289. doi: 10.1126/ science.aal 2541

Thomma, B. P. H. J., Eggermont, K., Penninckx, I. A. M. A., Mauch-Mani, B., Vogelsang, R., Cammue, B. P. A., et al. (1998). Separate jasmonate-dependent and salicylate-dependent defense-response pathways in Arabidopsis are essential for resistance to distinct microbial pathogens. Proc. Natl. Acad. Sci. U.S.A. 95, 15107-15111. doi: 10.1073/pnas.95.25.15107

Tsuda, K., and Katagiri, F. (2010). Comparing signaling mechanisms engaged in pattern-triggered and effector-triggered immunity. Curr. Opin. Plant Biol. 13, 459-465. doi: 10.1016/j.pbi.2010.04.006

Tsukada, Y., Fang, J., Erdjument-Bromage, H., Warren, M. E., Borchers, C. H., Tempst, P., et al. (2006). Histone demethylation by a family of JmjC domaincontaining proteins. Nature 439, 811-816. doi: 10.1038/nature04433
Vlot, A. C., Dempsey, D. A., and Klessig, D. F. (2009). Salicylic acid, a multifaceted hormone to combat disease. Annu. Rev. Phytopathol. 47, 177-206. doi: 10.1146/ annurev.phyto.050908.135202

Xiao, F. M., He, P., Abramovitch, R. B., Dawson, J. E., Nicholson, L. K., Sheen, J., et al. (2007). The N-terminal region of Pseudomonas type III effector AvrPtoB elicits Pto-dependent immunity and has two distinct virulence determinants. Plant J. 52, 595-614. doi: 10.1111/j.1365-313X.2007.03259.x

Yeh, Y. H., Chang, Y. H., Huang, P. Y., Huang, J. B., and Zimmerli, L. (2015). Enhanced Arabidopsis pattern-triggered immunity by overexpression of cysteine-rich receptor-like kinases. Front. Plant Sci. 6, 322. doi: 10.3389/fpls.2015.00322

Yeh, Y. H., Panzeri, D., Kadota, Y., Huang, Y. C., Huang, P. Y., Tao, C. N., et al. (2016). The Arabidopsis Malectin-Like/LRR-RLK IOS1 Is Critical for BAK1Dependent and BAK1-Independent Pattern-Triggered Immunity. Plant Cell 28, 1701-1721. doi: 10.1105/tpc.16.00313

Yekondi, S., Liang, F. C., Okuma, E., Radziejwoski, A., Mai, H. W., Swain, S., et al. (2017). Nonredundant functions of Arabidopsis LecRK-V.2 and LecRK-VII.1 in controlling stomatal immunity and jasmonate-mediated stomatal closure. New Phytol. Dec. 18, 253-268. doi: 10.1111/nph.14953

Zhu, J. K. (2009). Active DNA Demethylation Mediated by DNA Glycosylases. Annu. Rev. Genet. 43, 143-166. doi: 10.1146/annurev-genet-102108-134205 In.

Zimmerli, L., Metraux, J. P., and Mauch-Mani, B. (2001). beta-aminobutyric acidinduced protection of Arabidopsis against the necrotrophic fungus Botrytis cinerea. Plant Physiol. 126, 517-523. doi: 10.1104/pp.126.2.517

Zipfel, C., and Robatzek, S. (2010). Pathogen-associated molecular pattern-triggered immunity: veni, vidi...?. Plant Physiol. 154, 551-554. doi: 10.1104/pp.110.161547

Conflict of Interest: The authors declare that the research was conducted in the absence of any commercial or financial relationships that could be construed as a potential conflict of interest.

Copyright (c) 2019 Chan and Zimmerli. This is an open-access article distributed under the terms of the Creative Commons Attribution License (CC BY). The use, distribution or reproduction in other forums is permitted, provided the original author(s) and the copyright owner(s) are credited and that the original publication in this journal is cited, in accordance with accepted academic practice. No use, distribution or reproduction is permitted which does not comply with these terms. 